\title{
THE LONDON SUMMER 2012 OLYMPIC GAMES: THREAT OF DISRUPTION AND BUSINESS REACTION
}

\author{
ADAM JONES,* JANET WOOLLEY,* AND GRAHAM CURRIE† \\ *School of Sport and Service Management, University of Brighton, Eastbourne, UK \\ †Institute of Transport Studies, Monash University, Victoria, Australia
}

\begin{abstract}
The impact of and reaction to the disruption on transport created by mega-events on host communities and, in particular, businesses, is an underresearched area. Utilizing social exchange theory, this article examines the relationship between businesses and transport authorities in the implementation of the Travel Demand Management (TDM) strategy for the London Olympics 2012. This research identifies the mechanisms by which the authorities meet the specific antecedent conditions that impact on the exchange. This research is unusual as a qualitative approach is used to gain in-depth understanding of the impacts of mega-events on business and their attitudes to these antecedents. The theoretical contribution of this study is a model that depicts the decision-making processes by which businesses evaluate the exchange relationship. Results identify that there is a link between business typology, antecedent, and the level of engagement. The practical implications of the results and the limitations of the study are discussed with reference to future mega-events and research possibilities.
\end{abstract}

Key words: Mega-events; Olympics, Business; Travel demand management (TDM);

Social exchange theory

Introduction

Staging events has become increasingly important as cities endeavor to promote their image and market themselves (Brown, Chalip, Jago, Mules, \& Morgan, 2002; Deccio \& Baloglu, 2002; Fredline \& Faulkner, 2002; Jago, Chalip, Brown, Mules, \& Ali, 2003; C. Jones, 2001). Hosting the Olympic Games in particular is viewed as an opportunity for a city to promote itself on the global stage (Hall, 2006) and raise its worldwide profile (Ponsford \& Williams, 2010) through the international media (Boyko, 2008; Cegielski \& Mules, 2002; Fredline, 2005; Richards, Carlsen, Robertson, \& Ali-Knight, 2007; Small, Carlsen, Robertson, \& Ali-Knight, 2007) as "it is through television that the world experiences the Olympics" (Tomlinson, 1996, p. 583). With such expectation and the world's eyes on the 
Olympic city, there is a need to ensure hosting such a mega-event appears as a faultless operation.

Holding the Olympic Games is also regarded as an opportunity for achieving rejuvenation, economic and social development, nation building, or leading the way to political liberalization (Jessop, 2002). However, Flyvberg, Bruzelius, and Rothengatter (2003) believe academics need to reflect critically on the effects of hosting these events, especially their social-cultural impacts (Boyko, 2008; Cegielski \& Mules, 2002; Fredline, 2005; Richards et al., 2007; Small et al., 2007). Delivering the Games often requires government subsidies and places increased demands on public services (Chalip \& Leynes, 2002). Some argue that the reality of a mega-event, such as the Olympics, produces relatively few tangible benefits for the average citizen, who may actually suffer increased costs (Hiller, 2000).

The Olympic Games are unequalled in their scale and potential impact (O’Brien, 2006) and, as a consequence of their high profile, poor reputations can be especially enduring. Therefore, the "need to get it right” is vital (Dobson \& Sinnamon, 2001). The Montreal Olympics is primarily remembered as being financially burdened, Atlanta as traffic congested. The horrific events and images of Munich are still vivid in people's memories (Schimmel, 2006).

Expected benefits, used to legitimize support for such events (Hiller, 2000), are largely dependent on its success. As a consequence of the competition between cities to host mega-events, the negative impacts are frequently ignored, with political leaders and organizers glorifying the expected benefits (Gursoy \& Kendall, 2006). The judgment of the costs and benefits of mega-events may be complicated by desires for distributive justice and differing values of the community (Fredline \& Faulkner, 2002).

\section{Transport Issues at Previous Olympic Games}

Experiences from previous Olympic Games, in particular Atlanta 1996, highlight the transport problems faced by cities hosting mega-events. The Atlanta public transport system was not able to cope with the huge additional demands placed upon it (Bovy, 2010). This resulted in severe delays and crowding for both the visitors to the Games and the host population (Currie, 1998). The problems were not restricted to those that had come to see the Games; the athletes were also severely impacted by inadequate transport provision. Baseball games between Nicaragua and the US and between Japan and the Netherlands were delayed because the team bus was late, and one Olympic fencer arrived just 10 minutes before his competition was set to start (Applebome, 1996). These transport fears resulted in the British rowing medal hopeful, Steve Redgrave, moving out of the Olympic Village, afraid that transportation would not deliver him to his venue on time (Dobson \& Sinnamon, 2001). These problems resulted in unfavorable media coverage and the President of the IOC, Juan Antonio Samaranch, being prepared to credit the Atlanta Games only as a "qualified success" rather than the customary "best games ever" (Essex \& Chalkley, 2003).

\section{Importance of Transport}

Mega-events and hallmark events provide great opportunities and the "Olympic Games are widely considered the most prestigious of these hallmark events, drawing global attention to host cities" (Ponsford \& Williams, 2010, p. 17). However, they come with challenges as such events impose enormous demands on the urban environment, in particular the local transportation infrastructure (Currie \& Delbosc, 2011; Ritchie, 1984). These demands can result in general disruption and adverse social issues for local residents and businesses, including congestion (Barker, Page, \& Meyer, 2002; Dwyer, Mellor, Mistilis, \& Mules, 2000; Kim, Gursoy, \& Lee, 2006; Ohmann, Jones, \& Wilkes, 2006). The consequences of not accommodating the increased traffic volumes are so severe that political leaders are willing to put aside differences to create solutions (Giuliano, 1992). The Olympics are expected to test the transport system to the limit, with concerns "passed on from one Games to another almost as sacred as the Olympic Flame itself" (Hensher \& Brewer, 2002, p. 381).

The Olympic Games last for only 16 days. Large infrastructure projects to create additional transport capacity, therefore, cannot be justified on this basis alone. Investment for transport projects that would have been built at some time in the future to produce longer term benefits for the city (Kassens-Noor, 2012) are brought forward for the Games. Such projects, promised by the authorities in order to win 
the bid for the Games (Currie \& Delbosc, 2011), are referred to by Bovy (2010) as "Games accelerated transport projects” (p. 37). These have included: 116 kilometers of new rail lines for Atlanta, new rail links to the coast and airport for Athens, and increasing the number of underground lines from two to eight in Beijing (Bovy, 2007). However, such additional capacity is rarely enough to cater for the extra transport demand placed on the host city.

A mega-event is where the city's transport system and urban logistics are seriously impacted by the proceedings (Bovy, 2007) and, as Bovy (2006) observed, a "highly robust and resilient transport system is a prerequisite for handling exceptional mega-event traffic demands, and the implementation for such measures plays a vital role in the bidding process for cities to host such events" (p. 34). History has shown that the degree of success of the transport provision for mega-events depends on not only the quality and capacity of the host city's urban public transport network, but also how the transport demand within the city is regulated (Currie \& Shalaby, 2011; Giuliano, 1992). Regulating transport demand is an undertaking that requires extensive planning and management, and due to the fact that the Games is usually experienced only once in a lifetime in any one location, planning for the Olympics is similar to "shooting in the dark” (Ponsford \& Williams, 2010, p. 21). There are, therefore, exceptional transport planning management requirements.

\section{This Project: Aims, Objectives, and Methods}

Studies would suggest that residents' attitudes towards impacts affects their support for such events (Ap, 1992; Cheng \& Jarvis, 2010; Nunkoo \& Ramkisson, 2012; Perdue, Long, \& Allen,1990; Ward \& Berno, 2011) and host communities question to what extent the benefits of hosting megaevents offsets the costs (Haxton, 1999). Strategies to accommodate mega-events, such as changing commuter behavior, create complex indirect effects on both workers and the work place (Giuliano, 1992), as mega-event visitors share common location and similar travel times as the host population (Robbins, Dickinson, \& Calver, 2007). The impact of, and reaction to, disruption on transport created by mega-events on the host communities and, in particular, businesses, is an underresearched area.
The gap in the literature is surprising given the importance that cities and regions place on gaining the rights to hold mega-events, and the support that businesses are expected to provide to ensure the success of such events.

This article presents a case study on the impacts of the London 2012 Travel Demand Management (TMD) program on businesses in London. TDM is a technique used to manage specific increase in demand and is also a proven strategy for reducing recurrent demand (Tanaboriboon, 1994). Robbins et al. (2007) acknowledge "transport has not emerged as a core focus in the event management literature" (p. 303). The aim of this article, therefore, is to understand how businesses perceived the TDM program and how they reacted to it in terms of plans for the Games period. Social exchange theory (SET) is used as a conceptual framework in the analysis of businesses' response to this program. The theory is used to identify the cost-benefit relationship between business and the measures imposed. Due to the lack of previous research, this study is essentially exploratory. The article reviews literature on past Olympic Games, Transport for London (TfL), and the Olympic Delivery Authority (ODA) reports for London 2012, and draws upon the results of a series of qualitative interviews with businesses that would be impacted by TDM measures in and around London. The threat of disruption to usual business operations are perceived at different levels and strategies that are employed by businesses vary depending on their type, size, scope, and their ability and willingness to respond. This study demonstrates the importance of authorities in communicating policy, and the antecedents required to engage business are identified. Ap (1992) and Waitt's (2003) SET models are adapted and a scale of acceptance dependent on business typology is proposed.

\section{Transport Planning and Mega-Events}

Transport is required to ensure that both participants and spectators are able to travel with the least inconvenience to and from the event (Robbins et al., 2007). The traffic management program of the 1984 Los Angeles Summer Olympics was a resounding success, providing most residents and visitors better travel conditions than would normally have been experienced (Giuliano, 1992). The lesson of 
the Los Angeles Games have contributed to the development of Olympic TDM programs that have been used as a significant element in the transport planning for all Olympic games since Atlanta 1996 (Currie \& Delbosc, 2011). Planning for London 2012 was no exception, and TDM measures were a core component of TfL and London's Olympics Delivery Authority's (ODA) strategy to accommodate the expected increase in travel demand.

The aim of TDM, referred to as "the art of modifying travel behavior” (Ferguson, 1990, p. 442), is to maximize the people-moving capability of the transport system (Currie \& Delbosc, 2011) and is reliant upon transport users changing their usual travel behavior. TDM is appealing to authorities as, at little or no cost in comparison to infrastructure projects (Bautz, 1988), transportation efficiency can be increased. The implementation process, the attitudes, ability, and readiness of users to comply with such measures needs to be understood if such strategies are to be successfully implemented (Bhattacharjee, Haider, Tanaboriboon, \& Sinha, 1997). Authorities need the cooperation of the host city's businesses for such policies to be successful as they have influence and control over a substantial proportion of daily transport usage. Corporate stakeholder relationship and engagement is emerging as an important consideration for event management (Getz, 2002; Gursoy \& Kendall, 2006; Ponsford \& Williams, 2010) and, therefore, an understanding of business attitudes towards TDM and their willingness to engage is vital to ensure that future host city authorities can successfully implement these strategies.

Studies into business attitudes towards TDM are limited. However, research into work-based travel plans (TP) have been conducted. These have found that companies tended to implement a TP only when regulations required them to do so when faced with planning consent regulations, parking restrictions, or congestion problems (Enoch \& Potter, 2003). However, such "hard policies" were viewed by businesses as a cost, not a benefit, and companies engaged with them at the initial planning stage only to comply with regulations. TPs then tended to be relaxed and not actively promoted. This short-term effect has encouraged local governments to look at implementing a softer approach (Moser \& Bamberg, 2008), such as personalized travel planning, public transport marketing, and travel awareness campaigns. The success of such "softer policies," also known as voluntary changes, has been limited (Loukopoulos, 2007), and research has tended to focus on road rather than public transport use. Roby's (2010) survey of 25 organizations identified that TPs are starting to become embedded within business planning and are moving to a more strategic role within the company. Although not fully part of the organizations' Corporate Social Responsibility (CSR) agenda, Roby's research did suggest that TPs, linked to environmental policy, are a growing consideration in CSR implementation.

Government encouragement of business to engage in transport planning is central to any TDM strategy, whether for long-term urban congestion issues or for short-term planning, for an event such as the Olympics. TDM, including both hard and soft measurers, is used to accommodate the transport requirements that cannot be met by existing or planned infrastructure developments. Methods used in previous games include:

- Travel capacity creation measures - reduce demand using a wide range of measures such as timing major events at weekends or public holidays.

- Travel behavior change (or marketing) measures -reduce travel or change travel mode to a more efficient means, such as public transport or higher occupancy vehicles.

- Traffic efficiency measures - to improve traffic flow/delays such as adjusting traffic signal settings to maximize capacity and parking bans and tow truck use.

- Traffic bans - to remove or exclude traffic.

- Public transport emphasis measures-encourage higher capacity and more efficient transport modes, such as rail transit, to carry large volumes of travelers (Currie \& Delbosc, 2011).

The previous four Summer Olympic Games have all, depending upon the existing level of transport infrastructure and the geographical and political terrain of the host city, employed a range of TDM measures. As Table 1 demonstrates, these have proven highly successful in reducing "base load" demand, thus increasing the available capacity to handle the additional Olympic-generated travel. Sydney 2000 altered the dates of the school holidays to reduce 
Table 1

Summary of Estimated Base Load Demand Reduction—Olympic Games

\begin{tabular}{|c|c|}
\hline Location/Year & System-Wide Impact \\
\hline Beijing 2008 & $\begin{array}{l}\text { Traffic volumes fell by } 21 \% \text { and average speed } \\
\text { increased } 27 \% \\
\text { Total urban VKT dropped } 32 \% \text { and speed increased } \\
\text { from } 5 \mathrm{~km} / \mathrm{h} \text { to } 37 \mathrm{~km} / \mathrm{h}\end{array}$ \\
\hline Athens 2004 & $30 \%$ reduction in traffic levels on main roads \\
\hline Salt Lake City 2002 & Downtown traffic down $30 \%$ to $40 \%$ from normal levels \\
\hline Sydney 2000 & $\begin{array}{l}\text { Road traffic volumes reduced by } 10 \%-20 \% \text { of normal } \\
\text { weekday levels } \\
\text { Sydney’s general traffic decreased by } 20 \%, 15 \% \text { to } 20 \% \\
\text { reduction in daily traffic }\end{array}$ \\
\hline Atlanta 1996 & Weekday total 24-h traffic counts decreased by $2.8 \%$ \\
\hline Barcelona 1992 & $15 \%-20 \%$ reduction in congestion \\
\hline Los Angeles 1984 & $4 \%$ background reduction on highways \\
\hline
\end{tabular}

Source: Currie and Delbosc (2011).

demand and encouraged central business activity to relocate. To change behavior in Sydney, the authorities continually updated stakeholders about travel-related issues before and during the Games (Bovy, 2007). To increase traffic efficiency, Athens constructed a new traffic management center and implemented an extensive demand management system (Minis \& Tsamboulas, 2008). To remove traffic, Beijing implemented strict behavior changes that involved an "odd and even" system that required cars to stay off the roads on alternate days, depending on whether their license plate ended in an odd or even number (Bovy, 2007). Additionally, every Games since Sydney has actively encouraged the use of public transport (Currie \& Delbosc, 2011).

To engage the local population and business community, and gain their cooperation in reducing the "base load," a comprehensive public awareness campaign is required. The Sydney authorities, with a strategy of "underpromise and overdeliver" through a single PR agency, implemented a clear, unambiguous promotion of travel behavior change. Part of this strategy has been described as scare tactics or the "Big Scare" (Currie, 1998). The "Big Scare" reinforces apprehensions about the "travel chaos," which the Games might create in order to constructively influence travel choices (Currie \& Delbosc, 2011). Although not an acknowledged TDM strategy, such tactics have been attributed to travel behavior change measures (Clean Air in London, 2011; Currie \& Delbosc, 2011; Shawcross, 2011). The "Big Scare” is reliant upon a receptive media picking up on the worry of "travel chaos" caused by the games to create "scare" stories that positively reinforce the message that travel behavior change is needed (Currie, Jones, \& Woolley, 2013).

\section{London 2012 and its TDM Program}

Creation of the bid proposal to host the Olympics is often fast tracked, with cursory public consultation and incomplete evaluation of economic and social impact (Hall, 1992). As far back as 2003, 9 years before the London Games was scheduled to start, transport was deemed an integral component of planning and, by the time of the bids' submission, strategies to include transport infrastructure projects and the concept of a road network dedicated to Games traffic [the Olympic Route Network (ORN)] were already in place (Dosunmu, 2012). To ensure the delivery of the transport projects required by the Olympic governing body, the UK Government enacted the "London Olympics Act 2006." The act removed specific powers from the local traffic authorities and allocated them to the ODA, an unelected organization set up specifically for the delivery of the Games (A. Jones \& Woolley, 2013). In addition, the Act required the local highway, traffic, and street authority to obtain the consent of the ODA for any of its actions that may impact on the running of the 2012 Games (House of Lords, 2005). The implementation of the Games transport strategy involved a range of stakeholders, principally the ODA, London Organizing Committee of the Olympic Games 
(LOCOG), Department of Transport (DFT), TfL, The Highways Agency, Network Rail, train operating companies, and local authorities.

Peter Hendy, London Transport Commissioner, alluding to the scale of the task, described the transport provision for the Olympics as "the largest peacetime logistics exercise” (Hendy, 2012). The 2012 Summer Olympic Games, 16 days in duration, required a transport plan for handling an estimated additional 9 million visitors to London. Provision was also required for the expected 50,000 members of the Olympic Family; athletes, accredited media, and sports officials (Dosunmu, 2012). The requirement to "get it right" was vital for the success of the Games, and these additional visitors needed to be incorporated into a transport system that was already operating at near capacity.

The transport strategy included a number of key objectives: delivery of the ORN, enhancing the capacity of the public transport infrastructure, a multimodal Transport Coordination Center, a bespoke fleet of vehicles for the Olympics Games Family, and temporary enhancement to rail capacity and park-and-ride schemes (Dosunmu, 2012). Promoted as "The Public Transport Games," an important element of the underlying sustainability theme of the Games was that all spectators were expected to take public transport, walk, or cycle (TNSBMRB, 2012). Where there was legacy value, permanent transport infrastructures were developed. The London Olympics 2012 provided the justification for the continuation of a number of infrastructure projects that, as a result of the financial crisis of 2008, if not necessary for the Games success, could have been delayed or shelved entirely. These projects, involving $£ 15$ billion of transport investment, included the new Javelin high-speed train, an extension to the Docklands Light Railway, London Underground enhancements, and improvements to Stratford International and regional stations (Hendy, 2012; Kershaw, 2012). However, the ability to move the additional visitor load would also be reliant on enhancing the "existing capacity" of the system, utilizing TDM to reduce the base load. The London TDM policy, a temporary measure costing an estimated $£ 30$ million, was the largest in Olympic history (Currie et al., 2013), but must be viewed in comparison with the $£ 15$ billion that was invested in transport infrastructure projects.
The aims of the TDM project were to:

- Manage expectations - setting reasonable passenger and business expectations (i.e., plan your journey, plan to arrive early, expect delays).

- Manage total demand at hotspots-encouraging non-Games demand to reduce, retime, remode, or reroute their journey.

- Help optimize the Transport Network-providing passenger information with guidance and information to help make best use of the available capacity.

- Work closely with the business community-to minimize background demand and ensure continuity of business operation.

- Support transport reputation managementtransport becomes part of a positive Games story.

- Provide legacy foundations-long-term behavioral change, a legacy of sustainable travel (Olympic Delivery Authority [ODA], 2012).

Although the overall aims of the TDM project were far reaching, the objective of the ODA's TDM strategy appears simplistic in comparison. Bannered as "to influence enough people enough," its focus was to free up capacity on the existing transport system to allow for the increase in demand (ODA, 2012). This involved targeting the host population to reduce their overall travel use by working from home or changing their time, route, and mode of travel. Data from previous Olympic host cities identified an estimated 20-25\% reduction on usual non-Games demand would be needed. To achieve this target, the ODA (2012) estimated 35\% would come from a reduction in the number of trips, $29 \%$ from changing the time of travel, 32\% from altering the route, and 15\% from changing the mode of travel. Four work streams were put in place to achieve these reductions:

1. Travel advice to business - advice to businesses and other large trip-generating organizations.

2. Road freight management-managing background freight demand at Games time.

3. Marketing and communications - travel awareness campaigns

4. Traveler information services-including an online "Games Time Journey Planner" (GJP) and the provision of customer information (ODA, 2012). 
These programs commenced in 2009. The first public campaigns, mainly targeted at the business community, were launched in late 2010, with full activation and refinement of projects undertaken in late 2011.

\section{Promotion of Travel Advice to Businesses}

This study is primarily focused on the business community; the following gives a more detailed account of the travel advice to business work stream and a timeline of engagement.

Engaging with business (Table 2) was core to the ODA and TfL's policy. As large companies controlled travel patterns of a considerable numbers of employees' a bespoke one-to-one consultancy was launched early in the program. To be effective, such organizations would require time to plan any changes that they may be able or willing to implement in their daily working pattern. Later in the program, a range of initiatives aimed at reaching a broader range of businesses that would be affected during the Games was implemented.

The TDM strategy involved influencing everyday users of the transport system to alter their travel plans. Restrictions involving the road network would have impacts on freight organizations and businesses that were reliant on the roads for their daily business operation. The closure of some roads and "no-stopping" restrictions due to the ORN would result is such business having no choice but to alter their normal working practices.

As can be seen from the above data, to cater for the Games, the ODA and TfL implemented a comprehensive transport strategy, a core component of which was their TDM program. The success of this program was largely reliant on regular, non-Games users altering their travel behavior. As businesses influence the daily travel routines of their employees, early engagement with this community had formed a major component of TfL's TDM program.

\section{Theoretical Framework}

Social exchange theory, described by Emerson (1976) as a frame of reference that through the social process plots the flow of resources, implies a "two sided, mutually contingent, and mutually rewarding process involving 'transactions' or 'simple exchange”” (p. 336). SET has been adapted and developed to study the fields of leisure (Searle, 1991), tourism (Ap, 1992), and events (Waitt, 2003). It has been used to identify the range of host populations' attitudes, feelings, and evaluations towards impacts

Table 2

Travel Advice to Business Timeline

\begin{tabular}{|c|c|}
\hline Date Activity Started & Business Activity \\
\hline November 2010 & $\begin{array}{l}\text { Travel Advice to Business Toolkit—online information service } \\
\text { for business. }\end{array}$ \\
\hline November 2010 & $\begin{array}{l}\text { Site-specific advice program-a specialist one-to-one advice } \\
\text { service for larger organizations with operations in identi- } \\
\text { fied hotspot areas; } 533 \text { companies signed up for this service, } \\
\text { accounting for over } 611,000 \text { employees. } \\
\text { Presentations held by third parties and business intermediary } \\
\text { groups; } 333 \text { presentations held, attended by } 19,500 \text { businesses. } \\
\text { Launch of "Keep on Running”-business information and } \\
\text { awareness campaign. }\end{array}$ \\
\hline July 2011 & $\begin{array}{l}\text { Workshops held for SMEs; } 140 \text { workshops were held and } \\
\text { attended by 2,850 businesses. }\end{array}$ \\
\hline January 2012 & $\begin{array}{l}\text { Intense program of travel advice to businesses and freight-mail } \\
\text { drop to 45,000 businesses in central London. } \\
\text { Door to door leafletting; } 25,000 \text { SMEs in priority hotspots. } \\
21 \text { drop-in centers set up; } 965 \text { businesses made use of them. } \\
\text { Travel Advice to Business (TAB) newsletter; sent out to 10,000 } \\
\text { business and business intermediaries. }\end{array}$ \\
\hline
\end{tabular}

Source: ODA (2012); TfL personal communication, June 20, 2012. 
as a result of the received experiences (Ap, 1992; Cheng \& Jarvis, 2010; Haralambopoulos \& Pizam, 1996; Nunkoo \& Ramkisson, 2012; Pranic, Petric, \& Cetinic, 2012; Waitt, 2003). The host population will view the event as either positive or negative depending on the expected benefits they will receive or costs that they will incur as a result of the level of service/effort they employ. At a macrosociological level, Emerson (1976) identified that the concept of exchange was useful to analyze labor relations, interorganizational relations, urban community structures, and political science. Ap (1992) believed SET was useful in examining positive and negative perceptions at the individual or collective level. In this context, it analyzes policy implementation and communities' reaction. The authorities, in order to free capacity for Gamesrelated travel, required a reduction in commuters using the transport network. Businesses required the ability to operate as normal within a prosperous economic environment.

Faulkner and Tideswell (1997) highlighted intrinsic and extrinsic variables that impact in both the collective and individual exchange relationships. Intrinsic variables included host communities' demographic characteristics, location in relation to the event, and perceived evaluation of fairness. Extrinsic variables involved overarching themes of destination cultural identity, level of industrialization, and the ratio of visitor to the host community. However, more recent studies criticize the value of extrinsic variables as their influence on responses are too varied to support a theoretical framework (Fredline \& Faulkner, 1998). Impacts from and reaction to mega-events are not universal. The size and type of each event varies, as does the host community's industrial and social development size of the destination and political regime (Baker, 2004; Fredline, 2005). Zhou and Ap's (2008) study on the Beijing Olympics identified that residents' support for the Games was very high despite the fact that 93\% of those surveyed were not consulted in the planning process, a factor not necessarily acceptable in a less centralized society. This point is borne out by Pranic et al.'s (2012) study of the 2009 World Men's Handball Championship in Croatia. Perceptions of the exchange are also seen to be reliant upon a sense of trust in the policy makers and event organizers (Nunkoo \& Ramkisson, 2012).
This study, set in a developed democratic societal landscape, would be better compared to Waitt's (2003) study of the Sydney Olympics. Waitt used SET to research individuals' reaction to tourism and mega-events, where the urban population would expect an exchange to counter the costs of the impact. Waitt (2003) identified these costs as including "overcrowding, traffic congestion, and route disruption” (p. 196).

The Sydney study identified that as the start of the Games neared, public perceptions regarding the level of possible advantages in the form of economic benefits faded. However, the majority of residents still perceived the expected gains of the Games as outweighing the costs (Watt, 2003). This imbalance in the exchange could be explained by the concept of "altruism," whereby there is recognition that, even though there is a cost to individuals, others, the collective group or society, can be seen to benefit (Faulkner \& Tideswell, 1997). The concept of altruism is not evident in Cheng and Jarvis' (2010) study of Formula 1 in Singapore, where residents identified similar costs but the perceived positives were not valued highly enough to alleviate the imbalance in the exchange. The nature and impacts of the events, in this case Formula 1 in comparison to the Olympics, and the differing social-cultural composition of the host communities play influencing roles in the exchange (Fredline \& Faulkner, 2002).

The three altruistic themes that arose from Waitt's (2003) research, “community and national spirit, international promotion, and future business investment" (p. 209), show the Olympics is highly prized and, in this context, the wider positive benefits for the whole community and nation are deemed more important than the negative individual impacts (Haralambopoulos \& Pizam, 1996).

To understand and conceptualize business reaction to transport policy and its perceived impact, this study employs Ap's (1992) model of social exchange process (Fig. 1). Ap’s (1992) model, adapted from Searle (1991) and further adapted by Waitt (2003), identifies four antecedents: rationality, satisfying benefits, reciprocity, and the justice principle. These represent opportunities that need to be gained by at least one of the participants in the exchange relationship. Rationality is concerned with the reward/ benefit that the actor envisages the event would 


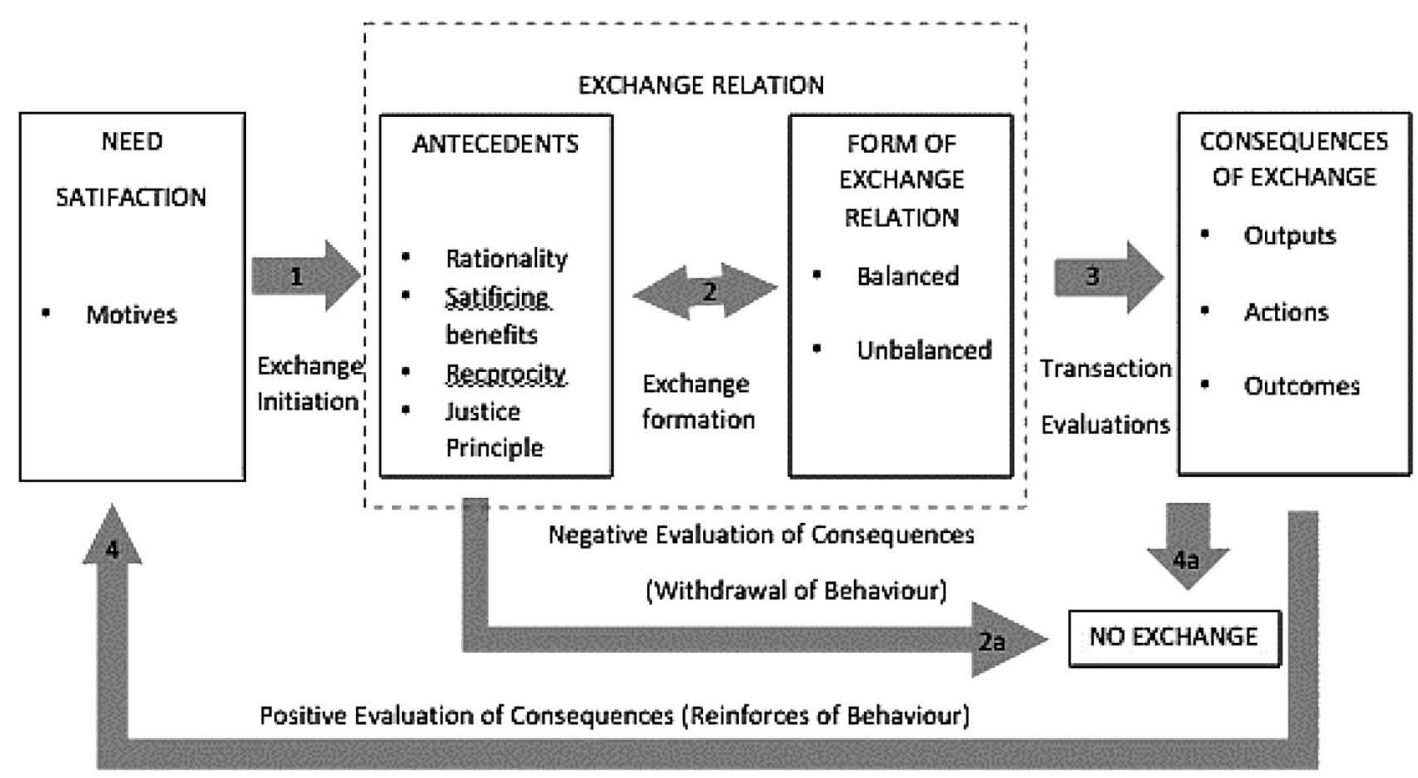

Figure 1. Model of social exchange theory. Source: Ap (1992).

bring while satisfying benefits demands that positive benefits must reach a satisfactory acceptance level. In the reciprocity, the exchange is evaluated in terms of equality. The justice principle employs the view that the exchange is underpinned by the concept of fairness and trust. The level of positive/ negative reaction is dependent on the level of control or influence within the exchange relationship (Ap, 1992; Sutton, 1967). Positive outcomes occur when the relationship is in balance, both participants have high levels of control, and there is an equal level of benefit. Negative reactions are experienced when participants have lower levels of control or influence, and little or unequal gain is expected from the exchange. Negative reactions result in the participants withdrawing and no exchange occurs, whereas a positive outcome will reinforce future behavior and exchange relations. The Olympics is a once-in-a-life-time event; therefore, the immediate exchange relationship, rather than future exchange, is important.

Wrong (1979) believes that power within SET relates to having controlling or influencing resources that someone else needs. In this study, resources involve the authorities' control of and access to the transport network, and businesses' influence over the transport users.

\section{Method}

Given the lack of empirical research in this field, this work is essentially exploratory in nature, using a case study methodology. Yin (2003) promotes case studies as a method that "arises out of the desire to understand complex social phenomena” (p. 2). They are valuable for understanding the "how" and the "why." Data for a case study "can include data from direct observation and systematic interviewing as well as public and private archives" (Yin, 2003, p. 249). Voss, Tsikriktsis, and Frohlich (2002) believe that case research can lead to "new and creative" insights and the development of theory that is valid for practitioners (p. 195).

Qualitative research as a method was selected as it provides a "thick description," which is the most appropriate to understand an organization's reaction to external impacts. The term "thick description" is used for texts that are salient for analytical interpretations (Geertz, 1973). In addition, qualitative research provides for in-depth analysis 
required to understand the reactions and decisions of businesses.

Data was collected from a variety of sources that, as Yin (2003) states, increases the reliability of the data. Initially, secondary data was collected. These data included the marketing and promotional material produced by the ODA, TfL, and other relevant authorities. Press releases and articles from the broadcast media that were in the public domain were also analyzed. These secondary data, especially the promotional material, provided the context and basis for evaluating the situation from a public perspective and was used to design some of the interview questions. Analysis of a variety of publically available sources such as web sites, documents, and presentations allows researchers to substantiate findings (Ponsford \& Williams, 2010). The reports and publicity material, especially those produced by the ODA and TfL, may be regarded as promoting a positive view on their policy. These publications were used by $\mathrm{TfL}$ as an impetus for organizations to consider engagement with TDM requirements and therefore provide data and information on their campaign.

Interviews were selected as the means of collecting primary data as they allow the researcher to probe further and gain a greater understanding of levels of engagement, reactions, and attitudes. Interviews provide an opportunity to identify inconsistencies and also provide a greater understanding of the reasons for them (Pettigrew, 1990). Fontana and Frey (1994) argue that structured interviews capture data that is codeable and precise, whereas unstructured interviews provide greater depth and understanding. In order to gain the benefits of both depth and coding, semistructured in-depth interviews were used, which, as Yin (2003) agrees, provide a "rich dialogue with the evidence" (p. 59).

The research required nonrandom sampling in order to "maximize understanding of the phenomenon” (Onwuegbuzie \& Leech, 2007, p. 111). Miles and Huberman (1994) defined 16 purposeful sample strategies, including one sample that "illustrates subgroups and facilitates comparisons" (p. 28). This sample technique was selected to enable analysis of the reaction of businesses impacted by TDM measures. The sample was varied by business size, sector, and geographical location. The sample specifically excluded businesses, such as sponsors, that were identified as direct beneficiaries of the Games as their attitudes and reactions to the impacts could have been skewed. The researchers were not aware when selecting the sample or during the research if any of the organizations had bid to become sponsors or a beneficiary but were unsuccessful.

Businesses in the study ranged in size from sole traders to midsized businesses employing 100s, to multinationals employing 1,000s. Respondents were recruited using a combination of convenience sampling of contacts known to the researchers and snowball techniques. Convenience sampling is a practical method of securing respondents whereas snowball sampling (also known as chain-referral samples; Heckathorn, 2002) enables recruitment of those who are willing, able, and appropriate.

The sectors sampled included those involved with financial services, professional services, wholesalers, and those operating in the field of logistics. Though not all were aware of the issues before the research commenced, in all cases it had been identified by the researchers that due to their location, the business would be impacted by TDM measures. Interviews were conducted with respondents who either had responsibility or were involved in preparing the organization for possible impacts of the Olympics. For small and medium-sized organizations, interviewees were either managing directors or members of the senior operational team, such as HR directors or senior partners. Larger organizations provided access to those whose role included responsibility for or involvement with business continuity. To facilitate the interview process, and cause as little disruption as possible to respondents, the researchers visited the participants in their offices in London.

The researchers also interviewed an organization representing small business, the Federation of Small Business (FSB). The FSB provided data on a segment whose response to the impact of TDM and the Olympics would be hard to capture on an individual level. In addition, a property management company that represented a large number of businesses in a central London location was interviewed. These provided an overarching view that helped confirm the accuracy of the findings of the sample. Representatives of TfL's TDM department were also interviewed to supplement secondary sources and provide insight into the TDM process and measures being implemented. 
Primary data from 15 semistructured interviews taking place between February and June 2012 were collected. These interviews lasted from 25 minutes to 1 hour 20 minutes. All were, with permission, digitally recorded and transcribed. Each interviewee received a standard interview guide explaining the intention of the research and the areas that would be covered. The interview guide provides assurance to the interviewee that the researcher is competent and ensures the interview concentrates on the phenomena being investigated (Meuser \& Nagel, 2002). The guide contained 10 questions to understanding the context of the organization, gather information on the interviewees' level of awareness of TDM, and ascertain the company's planning for the impacts of the Games. All interviews were attended by both researchers, which allowed for shared perspectives to be discussed and contrasted postinterview (Roper, 2004).

The data were analyzed iteratively both during and after collection. Notes were made after each interview before transcripts were created, as Miles and Huberman (1994) state that this allows allow for a "perspective that combines immediacy with a reflective overview of what went on" (p. 52) and the process may identify questions to be asked of the next interviewee. Analysis of the data followed the steps identified by Auerbach and Silverstein (2003), where repeating ideas were grouped together and then organized into themes that could then be grouped into abstract categories.

\section{Findings}

The cornerstone of TfL's TDM strategy was to "encourage enough businesses enough," which was dependent on successful business engagement. It is important to understand how businesses were engaged. Did they understand the message, what was their reaction, and what were their plans and responses? For the future planning of mega-events, it is necessary to reflect on the strategy employed by TfL, and evaluate why businesses reacted in the manner in which they did and their attitude to TDM. Our research findings have been broken down into three sections:

1. How businesses had been informed and their level of understanding of the impact of TDM.
2. How they planned to react to these measures and why.

3. How they felt about the demands being made of them and the anticipated effect on their business.

\section{Business Engagement}

Many of the businesses that were interviewed identified that transport in London would be a significant issue for their operation during the Games. Right from the time of the announcement that London had won the bid to hold the Games, some questioned the decision to accommodate such a mega-event in an already congested city. "I must say I was a bit negative about it, [bidding for the Games] because I thought we can't even run the transport system, and London is a nightmare to deliver around” (Howard, small fresh produce business).

Larger organizations, with in-house business continuity departments, started their initial planning processes 2 years before being formally contacted by TfL's one-to-one consultancy, SiteSpecific Advice Program. All the large organizations that were interviewed, companies in excess of 2,500 employees and located in central London, took advantage of the consultancy offered. They appreciated the bespoke service. However, some questioned the additional value provided. This could be attributed to the fact that these organizations had extensive business continuity departments whose role is to plan for such eventualities. “To be honest, I don't think that we benefited. I don't think there is anything that they pointed out that we wouldn't have had on our radar anyway" (Adam, banking 1). Others believed "We were getting their best practice-or understanding best practice from what others were doing” (Sean, financial services).

This one-to-one planning policy provided TfL the opportunity to ensure that companies had a comprehensive understanding of the problems involved.

They (TfL) sort of ran over the rational for their role ... in trying to enable London to run as a city and at the same time as making sure the Olympics worked as a Games ... a and they really said-you have a choice, you either communicate with people and buy into this and do it ... or it will be very disruptive. (Sean) 
These large organizations clearly understood TfL's message and the role they could play in ensuring transport disruption was kept to a minimum, thus in turn minimizing the adverse effects on their business continuity.

TfL's policy for engaging medium-sized businesses was centered on the involvement of a third party. These third parties, which included professional bodies, large suppliers, and Olympic sponsors, invited businesses to workshops where TfL presented their "Keep on Running” for business program. The objectives of which were "to deliver a great Games" and to "keep London moving" (ODA, 2010). The message was communicated through a PowerPoint presentation depicting the extensive level of research and modeling undertaken by TfL. This predicted the delays on the public transport network and detailed the restrictions and expected impacts of the ORN. Information presented gave, by underground and railway station, the anticipated delay times if there was no reduction in the base load and how the length of the delay would be reduced depending upon percentage decrease in the base load. The clear message from the presentation was that the problems that occurred due to poor transport planning at past Olympics, in particular Atlanta 1996, would not happen if businesses engaged with TDM measures to reduce, retime, remode, and reroute.

Some businesses were surprised that TfL was not providing additional capacity and was expecting businesses to take on the responsibility to help reduce the base load. "It was billed as a review of the contingency plans that TfL had in place for the Games period . . . the message I got out of it was actually there is no contingency plan" (Simon, engineering consultancy). Simon reinforced this by saying that the message given was clear: "if you change your working practices, it will be a lot easier for everyone else.”

The most poignant aspect of the presentation, identified by both large and medium-sized businesses, was an image portraying thousands of spectators reportedly queuing for a train (Fig. 2). "They showed us this picture, it was of the Atlanta Olympic Games, that is how not to do it, people were taking 9 hours" (Simon). "People were queuing up to 8 hours to get on to a train. It was a fantastic photograph” (Claire, architect's practice). All voluntarily commented on this picture, which they believed very clearly portrayed a worst case scenario. When asked their opinion on why TfL used this image, they believed it was to shock them. "Possibly it was all to totally terrify us and make us go 'God, we have got to do something!' " (Claire). The image had the effect of confirming the level of the disruption that could be created. "I do think that the figures were quite scary. So I trusted that- that it was the right [thing to do] I did come out of that thinking 'phew, we need to do something' about it” (Claire).

The research identified that engagement between TfL and small business was, to a large extent, initiated by the businesses themselves. Tim, from the London branch of the FSB, stated that they had to contact the authorities first. "We have been heavily involved on the lobbying and transport side (TfL and Locog), in particular to do with the Olympic and the Paralympic Route network.” This was further confirmed by Lilly, marketing services business owner, "No, no, it has not been raised with me by anybody, you know, like TfL.” Don, fish market representative, believed that it was only after he raised concerns with the press of the impacts from the ORN that TfL got in contact. "Words were spoken here there and everywhere, I think, to Transport for London, and we had a meeting with them, within the next fortnight from that interview with Reuters" (Don).

Once engagement was initiated, both Don and Tim applauded the level of effort TfL undertook to help in preparation for the predicted transport disruption. "And they [TfL] have made people available and, we have had two or three sessions in the market here with all the traders present, able to ask questions" (Don).

Small businesses, which, as Tim stated "by their very nature are short-termist,” are difficult to engage and, therefore, required a different approach.

They realize they [TfL] are not pulling enough small businesses to the seminars that they would like, so they are going to them and knocking on doors, and having discussion there on the business premises and that is what we want to see. (Tim)

London's small businesses are a diverse group and it proved difficult for TfL to formally engage with them all. Therefore, much of the information they received was via the press. Stories that 


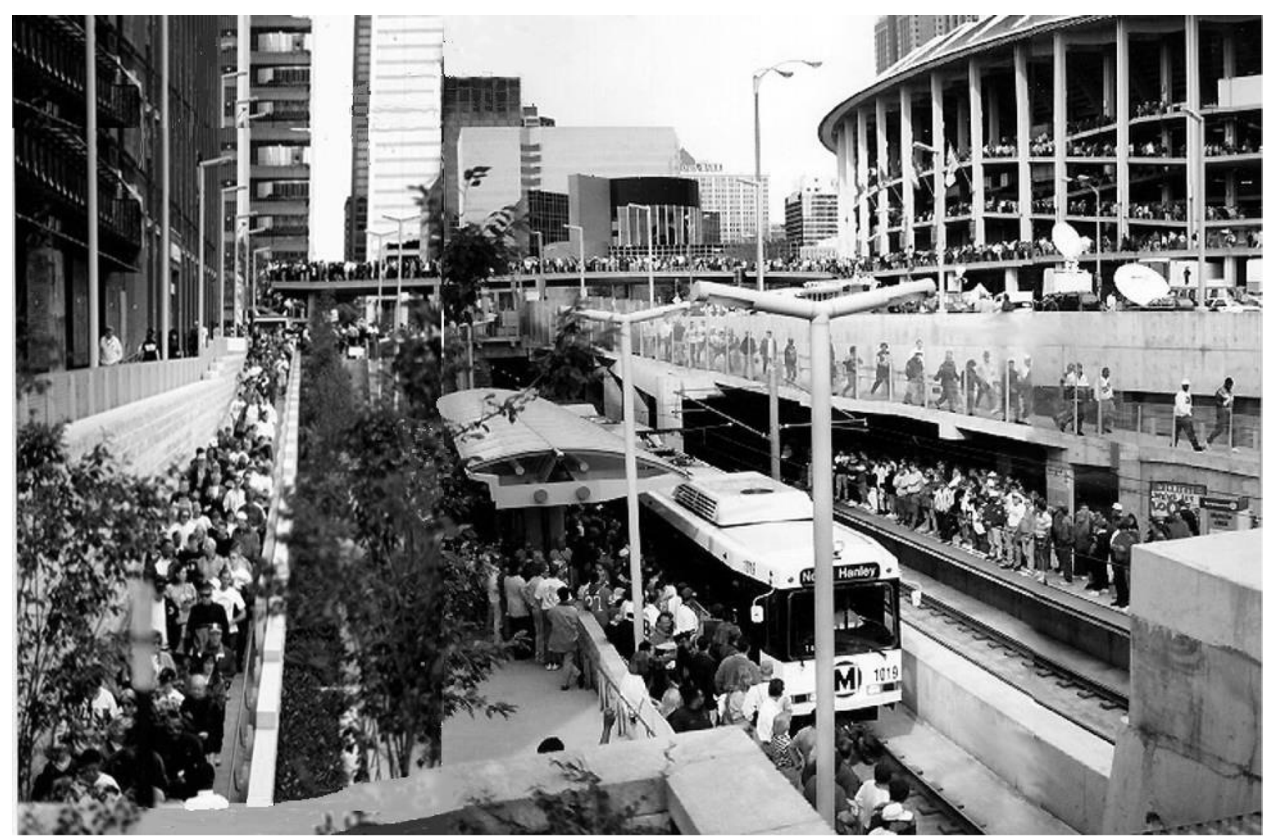

Figure 2. Picture of event crowding presented by TfL—said to be Atlanta 1996 Games. From Haxton PA. Olympic Games. Unpublished Ph.D. thesis, Sydney. University of Technology 1999. The Perceived Role of Community Involvement in the Mega-Event Hosting Process: A Case Study of the Atlanta 1996 and Sydney 2000 Olympic Games. (This picture was presented to the Olympic Delivery Authority by Professor Currie on February 2, 2010. It was adopted by TfL in their TDM program but incorrectly associated with the Atlanta 1996 games. It is a photograph from St Louis, MO, USA.)

appeared in the media played a not-insignificant role in informing and shaping opinions of the anticipated disruption to the transport system. Press articles, depicting a negative image of the possible problems to the public transport system, could aid TfL in achieving its objectives. Sean believed such stories helped gain management attention. "An article appears front page of the [London Evening] Standard, and, all of a sudden, our lead partnership is going 'hang on, maybe we do need to focus a bit of attention on this at this time." "

TfL claimed to have little or no influence over the media and some stories that were circulating were described as hysteria. "A lot of it is scare mongering really, we think. The information being put out that you are not going to be able to use the majority of the London road network is quite a myth, actually" (Tim).

Such inaccuracies, although raising awareness, can develop hostile reactions to the Games and be counter to the communication objectives. As a result, businesses were very worried that the message being received was that "London is not open for business" (Tim). There was also considerable confusion over the length of time the ORN would be in operation. Those directly affected by it originally understood that the restrictions would be imposed for 100 days. Don's initial reaction (to the Olympics) was:
We are thrilled to bits apart from the fact that the roads are going to be restricted for 100 days. It would have a devastating effect, it will be a very, very sad day if the outcome of the Olympics was to do something that two world wars could not, close the market.

When TfL corrected this misinformation, these companies were able to create more realistic plans. "When it was relaxed down to 2 days before and 2 days after, everybody has breathed a sigh of relief. It is not a problem, we can cope with it” (Dave, logistics). 


\section{Proposed Actions as a Result of Engagement}

Businesses' ability and willingness to cooperate and implement TDM measures varied depending on the size, location, nature, and level of autonomy over their operations. Large businesses that, due to their global presence, had experience of previous Olympics could, as Sean explained "replicate their governance structure and decision-making process that they had in their Sydney office.” Such companies did not appear to require such a personalized level of help from TfL. However, it was evident that TfL needed to be sure that these large organizations were clearly informed, proactive, and engaged. The level to which these larger businesses were asked to engage was borne out by Sean: "And they came to us and said, you know we are looking for organizations across London to reduce their Auguston-August transport by $40 \%$." The target requested by TfL ranged from $30 \%$ to $40 \%$ reduction on the base load at peak times. Barry (property management company) confirmed this: "We are going to be looking at about a $30-35 \%$ reduction of people [on a total of 110,000 commuters] coming into the estate at peak times.”

For the large organizations contacted, most felt confident that they could reach the target if not exceed it. These companies were already implementing flexible working practices.

We have working from home as part of our general "business as usual" strategy for most business areas. So what we are saying is, use this as part of your resource planning for the Olympics. You have got full executive support to do that. (Adam)

Although working from home would provide the largest percentage reduction in the base load, other aspects of the TDM strategy were being positively promoted. Adam requested employees to "Think about coming into work earlier and leaving earlier or coming in later and leaving later, working from a different location. Alter the way you travel, to walking, cycling, river boat.” In the main, these large organizations were happy to go beyond the initial request from the transport authorities. "We will be anticipating around $60 \%$ of our normal business as usual (BAU) population—a drop by 40\%” (Adam). This figure would relate to a reduction of 6,000 on a population of 15,000 employees. Sean's company was at first reluctant to reduce but became more compliant once the one-to-one consultancy allowed them to understand fully the implications for their business. Sean asked TfL "How aggressive do you want us to be in terms of people coming into our office, what sort of message do you want us to try and achieve?" TfL's response was clear: "Go for reduce-go for reduce as hard as you can, as there are so many organizations who cannot reduce. We would suggest for your benefit, and for the bigger picture, that you reduce as much as possible.” This large financial service organization, out of a work force of 5,000, was planning "at least a $60-70 \%$ reduction in heads.” They planned virtually to close their main office to client contact. Our research identified that such large organizations, due to their flexible working patterns, were able to reduce using a combination of additional leave, a working from home policy, and relocation.

TfL's strategy of targeting large organizations appeared to have the desired effect in helping to ensure that a sizable percentage of the workforce was given the opportunity to either remode, reroute, retime, or, importantly, reduce. However, not all the large organizations that we interviewed were so compliant. Although all large companies had the benefit of the one-to-one consultancy service, one of the large organizations we interviewed, which employed over 2,500 staff in central London, did not feel able or willing to make the changes to their business operations. They did put in place contingency plans for senior executives to stay in hotels or work from an out-of-town office. However, as Mark (banking 2) said "We won't be shifting people to [work from] home." The company had not ignored the problem as they had regular crisis management meetings and HR communications to staff. They adopted the position that it was their employees' responsibility to make arrangements to get to work on time. "The fact that you are late for work, you cannot blame the Olympics for it, it is about you adapting to additional time elements" (Mark).

Although Mark's organization was not complying with TfL's requests, they did plan to review the situation during the Games. Due to their meetings with TfL, they understood that there would be transport issues as their main office building was located directly on the ORN. However, their policy 
was one of "it is really 'suck it and see' and see what does actually happen on day 1" (Mark).

For the medium-sized organizations interviewed, their response to TDM requirements depended on their working practices, the level of engagement they received from $\mathrm{TfL}$, and their evaluation of the level of impact they anticipated the transport disruption would have on their ability to operate as normal.

Organizations in which their business was reliant on access to the road network had no option but to consider altering their operation. A fish market, comprising 150 separate traders, employing 500 staff, and directly located on the ORN, undertook a complete review of their procedures. "The whole operation is going to be brought forward by a couple or 3 hours-but it is going to need a lot of cooperation by a lot of people within the trade” (Don).

These changes would also impact many of their stakeholders. "There are hundreds of people in the market, but of course, transport officials, coastal suppliers - there are thousands of people that will be affected. In fact, we have to find a way of getting through it because it is a matter of survival” (Don). There was uncertainty concerning how successful their contingency planning would be able to cope as they were operating in an unknown environment. "Literally take it day-by-day and I know it is an old cliché but it is going to be that way” (Don).

TfL promoted the ORN as affecting a minimal percentage of London's roads. Although they say only $1 \%$ of London's roads will be taken up by the ORN, which is true, it just happens to be that this $1 \%$ of London's streets are the major routes and the major arteries which will affect us. (Dave)

This company planned to alter their operation "to work around these peaks, those that can take delivery out of hours we will be delivering out of hours. We will try and stockpile on site where it will not affect progress" (Dave). This approach was consistent with that taken by the freight industry: "the collective view [of the freight industry] is there was going to be a problem and they were prepared to do whatever was necessary, working with TfL to overcome the problems" (Dave). There was recognition by these organizations that they had no option but to change and engage with TDM as they had no control over the ORN restrictions.
Other medium-sized organizations, not forced into compliance due to ORN restrictions, held a different view. Although the message from TfL was clear, their reactions varied. Responses ranged from "business as usual," "No one was really bothered because we just have to get people into the office" (Simon), to "business as unusual," changing working hours, "so rather than starting at 9 o'clock we are looking at shifting that person, who is seriously affected, [to] starting at 12 and finishing at 8” (Claire).

These companies did not discuss reducing. There was no option of working from home; the responsibility was passed to their employees, who either had to get in on time for their normal working hours, or for an agreed "flexible" work pattern.

However, all the companies that were contacted thought they could use the Olympics to bring some positive benefits to their organization and employees. It would be used to "help enthuse the spirit of the Olympics and help incentivize people to want to come to work" (Claire). Other organizations went further. "Actually, we have given everyone an 'Olympic Day' so they can take one day off during the 2-week period” (Jonathon, PR agency). Some wanted to promote the festival spirit: "we will put lots of tellys up and have lots of drinks, make a bit of a party of it” (June, film production). In general, medium-sized businesses understood the situation and, unless they were forced to change due to the ORN, there was little other than limited retiming that they were prepared to do.

Small and microbusinesses found it difficult to change. If a business has "two members of staff and they need to be in central London, they just can't shut operations otherwise their business will fold" (Tim). Tim identified that the "negative impact of transport is the major concern of our members." Surveys carried out by the FSB reported that these organizations were increasingly nervous about transport and parking issues as a consequence of the ORN. Research of their members identified that "negative impacts have gone from 25\% in May 2011 to 50\% in December 2011” (Tim). Small businesses felt themselves powerless to plan in advance. "If you speak to a lot of London businesses, that is it, they are going hand to mouth and it is day to day at the moment" (Tim). As Howard emphasized: "It is up to the individual operators to look out for themselves." 


\section{Businesses’Attitudes Towards TDM}

The attitude of business varies from fully supportive of TfL's TDM policy, willing and able to help, to being unsympathetic to the requests and demands and extremely concerned by the possible impact on their business. Our research indicates this difference could be attributed to factors such as the amount of disruption that they envisaged, the level of control over their operation, and the degree of influence and involvement they had in the relationship with the transport authorities.

Large organizations, as part of their normal business operation, were aware of the implications of TDM and had plans in place to alleviate most eventualities. As Brian (banking 1) explained, "It is part of your year, [it's] in the calendar. The Olympics is just an additional one that has been put in there where we have had to place more emphasis." When discussing their preparations for the possible impacts and changes required for the disruption, a "corporate memory" is referred to:

There is an element of corporate memory involved with this as well, in that, not to put too fine a point on it, but Adam and I sitting in a room between us [we] could probably think of $99 \%$ of all the issues and what the solutions would be when these things happen. (Brian banking 1)

Such organizations were able to gain confidence from past experience, have the resources to enable them to plan, and were, therefore, able and willing to support TfL in its TDM objectives.

Interesting to note is the extent to which large businesses were prepared to help TfL in reducing the base load. These organizations were willing to go even further than originally requested "for the bigger picture benefit” (Sean). To achieve this, companies agreed to employ drastic measures, which could have a negative effect on their business. "This building is closed for client meetings, only a skeleton population, we would expect our profitability to struggle directly because of the Olympics” (Sean). Preparations were being made even though there was doubt that the congestion problems may not be that great. “No, I don't think they [senior management] think it is going to be bad. I think that they just want us to be prepared” (Adam).
Although these companies questioned the severity of the problem, and recognized that they may well have incurred additional costs or loss of revenue, they believed that they had a responsibility to help ensure the Games were a success. "As a good citizen of London, it's what we should do; it's our 'London responsibility,' our 'London social responsibility.' You could say it's part of our Corporate Social Responsibility (CSR) program” (Paul, finance industry group).

This attitude was not true of all large organizations. "Well, at the end of the day, we have a business to maintain" (Mark). They adopted a position that "there is a business case that has to be built for that, and the Olympics is not a justifiable business case" (Mark). The different responses to the engagement policy, made by similar large businesses, highlight the complexity of TfLs objective of "influencing enough people enough."

Medium-sized businesses had limited scope or expertise to enable them to voluntarily alter their business operations. However, when they had no option but to comply, they developed contingency plans. These companies were initially "horrified" when they heard about the restriction of ORN and believed it could result in serious consequences. "The initial report told us it [ORN] was going to be 100 days-it would have a devastating effect" (Don). Once TfL started their engagement, clarifying the full implications of the ORN, they "were prepared to do whatever was necessary working with TfL to overcome the problems" (Dave). This was true even though these changes could impact on their profitability.

There will be some additional operating costs, but we also know we have a client base and a very loyal client base, and we have to provide a service during this period. If it costs $1 \%$ or $2 \%$ morethen that is something we have got to take on the chin. (Dave)

There was a realization that, due to transport restrictions, they would be unable to take full advantage of the possible benefits of holding the Olympics in London. "We would love to show the market off, unfortunately, these hundreds or thousands or millions of people won't be able to get to see us" (Don). 
Despite the negative impacts, the consensus view was supportive of hosting the Games in London. "As a company, [if] it is the question, would we rather have had the Olympics in Paris or [in London] we would rather have them in London?" (Dave). "So yes, in spite of all the pessimism about the timings, and goodness me, how we are going to get through all this, there is still a great enthusiasm" (Don).

Medium-sized companies not impacted by road restrictions, and those that were implementing only a limited retiming policy, were originally surprised by the message from TfL. "So, the emphasis is clearly on businesses changing the way we operate over that period of time. And I think that didn't necessarily go down well with people” (Simon). These organizations, mostly professional services, were confident in relying on their staff's resilience to overcome whatever traffic disruption occurred. "And I think given the experience when it snows, when there are transport crises, and when there are tube strikes, $95 \%$ to $100 \%$ of our staff gets in every day. We are taking a bit of the same attitude" (June).

Those companies operating "business as usual" recognized that they were also relying on other companies complying with TDM measures. "I am hoping some people will take the advice and work at home, give us some sort of space [on the transport network]" (June).

The overall attitude of medium-sized businesses when asked to consider their reaction to the Olympics being held in London was also positive. "So, I think for London PLC it is a really good idea. London is going to be buzzing and it is going to be fun" (Jonathon). "We want the Olympics to be successful. We are quite proud so, you know, if we have to put up with a bit of hassle then that is absolutely fine, as long as it doesn't fundamentally affect our business" (Lilly).

Small businesses were the most fearful of the impacts of the TDM measures, the ORN in particular. They had little influence over the changes that were being imposed by the authorities. The short-term nature of their business, and with limited resources, meant they had few options with regard to how they could change their business operation; they also had little influence over their customers. These businesses were fearful of the impacts of the Games, which could be attributed to TfL's limited and late engagement with them. "Some of them will be able to [adjust], through gritted teeth" (Tim). It is not surprising that these businesses were concerned as the imposition of the ORN was adding to the challenges of operating in difficult economic times.

Yes, it is really sort of dog-eat-dog at the moment and you have to keep your customers. And if they say no, and insist that it gets there at the normal time of eleven o'clock in the morning, somehow you have to work to that. (Howard)

Although small businesses worried about the immediate impact, they were still hoping that the Olympics would be good for London in the longer term.

We genuinely hope that there will be this bounce, that won't just be seen through the Games but after it. Particularly on the tourism side, it will be felt for years to come. There is kind of a 2-year period where we think that London has that kind of place in the sun. And we do hope that we see those longterm benefits-whether it is procurement or just people coming to invest in London. (Tim)

\section{Analysis}

The results have indicated that businesses' implementation of TDM depended on the level of engagement they received from TfL. This directly impacted on their understanding of the requirements of the policy, their perceived influence and control over their ability to comply, and their attitude towards the impacts of the measures.

Figure 3 depicts a proposed decision-making process model developed from the findings of this research that describes the process by which businesses evaluated their response to TDM measures. This is adapted from Ap (1992) and Waitt's (2003) models of social exchange that were related to tourist events where the type of event, length of operation, location, and number of participants influences the initiation of the exchange.

The Olympics is normally a one-off engagement that requires specific policies to be implemented, in this instance TDM. The level of engagement by authorities directly affects businesses' evaluation of the antecedents of rationality, reciprocity, satisfying 


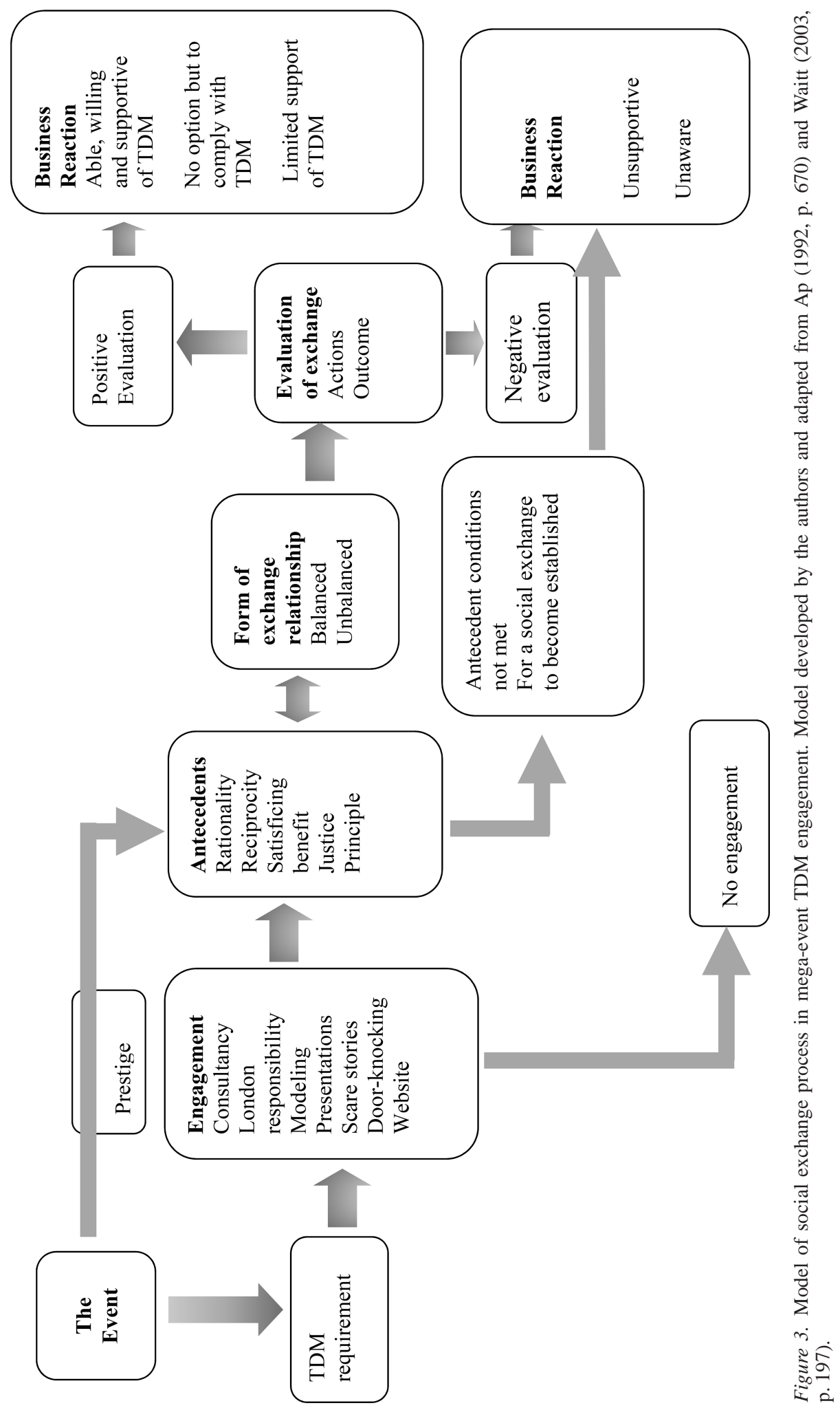


benefit, and the justice principle. The event itself, its prestige and kudos, will also impact on this evaluation. The TDM requirements are distilled into an engagement strategy that promotes the antecedent conditions that are required for a positive exchange relationship. Rationality is the business evaluation of the reward that engaging in TDM measures will provide, while satisfying benefits is weighing the balance of the cost of engaging in TDM against the cost of not doing so. For a positive outcome, businesses must believe that by engaging in TDM and employing a reduce, retime, remode, or reroute strategy, the transport infrastructure will cope and their operation will be able to continue as effectively as possible.

The cost-benefit analysis enables the businesses to evaluate the resource exchange as being at a satisfactory level and, thus, meeting the satisfying benefit antecedent. Reciprocity is evident when the level of planning and resources employed by $\mathrm{TfL}$ are evaluated as equal by businesses in relation to their planned engagement with TDM. The fairness or the justice principle of the exchange is gained by involvement of large businesses in the planning process, by the one to one consultants, and the use of extensive modeling that allows businesses to trust the data.

Businesses that are unaware of TDM will not engage in the exchange relationship and, therefore, there is no response or plans to change travel behavior. However, businesses that are aware and engaged enter into an exchange relationship. Depending on the balance they will evaluate the exchange as either positive or negative. This will then produce differing reactions depending on the evaluation and the level of perceived impact.

TfL's communication to large organizations, through their "Site Specific Advice" program, was very effective in informing these companies of the implications of TDM and encouraging engagement. Though most of these companies did not require the expertise of a one-to-one consultant, this personalized service was an effective strategy to ensure their support. The antecedents of rationality, reciprocity, and satisfying benefit were realized by these companies as they clearly understood the impact of the Games on their operations. They understood that by engaging with TDM, they could lesson negative impacts. Although this effective, personalized service targeted only a relatively small number of organizations, the latter all had influence over a sizable proportion of "non-Games demand" (their employees) and were, therefore, able to significantly help TfL meet its targets. Although TfL's overall objective was a $20 \%$ reduction in traveling, they asked these businesses to reduce by between $30-40 \%$, and it is noteworthy that in some instances businesses responded with a plan that would deliver a 50-70\% reduction. These businesses felt TfL's demands were justified and through the personalized service were kept involved and in control of their plans. The evaluation of the exchange was positive, all antecedents, including the justice principle, being realized, creating a balanced exchange with companies feeling in control. This may explain why such businesses were happy to go beyond TfL's initial request, even though they would not directly benefit financially from the Games and may well incur additional costs. These organizations and TfL developed a "mutually contingent relationship" (Emerson, 1976, p. 336), each recognizing the benefits of their exchange. There could also be an altruistic element to this response, as large organizations regarded engaging with TDM as part of their corporate responsibility to the city. Their response mirrors Waitt's (2003) altruistic themes of community and national spirit, international promotions, and future business investment. The success of "soft" measures (Moser \& Bamberg, 2008) employed by TfL in their engagement strategy is encouraging. These results contradict Loukopoulos's (2007) findings on the effectiveness of "soft measures." Businesses viewing participating in TDM as part of their CSR strategy also concur with Roby's (2010) findings on work-placed travel plans. However, it is questionable whether these organizations would have had such a positive evaluation of the exchange if this was not a prestigious one-off event.

Education was an essential component of TfL's engagement strategy for medium-sized businesses as they had no prior understanding of the requirements of TDM. There was a belief that TfL would provide alternative options to alleviate any possible disruption. The lack of alternatives resulted in the antecedent of reciprocity not being met. The message from TfL was consistent with that given to large organizations. However, these businesses' responses were that 
they could not or would not reduce but would, where essential, implement a retiming policy. This partial engagement would indicate an imbalance within the exchange for these businesses. Although TfL did not achieve planning for a significant reduction in the base load from all the medium-sized businesses interviewed, they did achieve some TDM objectives, in particular "retime." Their engagement ensured some of these businesses realized antecedents of rationality, and satisfying benefit, as they valued the information and the ability to make informed decisions. The information provided allowed for some balance in the exchange as these organizations could ensure "business continuity" and also support Tfl's “Transport Reputation Management," two key aims of the TDM project. Elements of the justice principle were also apparent as the organizations that attended TfL's business engagement presentations believed that they were well informed. They appreciated the level of engagement and, due to the extensive modeling that TfL had undertaken, trusted the information provided to identify the level of impact on their business. Although only some of the antecedents were realized, this allowed for a balance in the exchange and a positive evaluation and some engagement in TDM. This differs from Ap (1992), where all antecedents need to be realized for a positive outcome.

However, Ap (1992) and Sutton (1967) identified involvement in the planning process, trust, and the evaluation of fairness as important elements in the exchange relationship. Nunkoo et al.'s (2012) research further supports this, suggesting that trust in government planning and a feeling of empowerment leads to support. These businesses may not appear to have a high level of control in relations between themselves and TfL, but their positive attitude and subsequent level of engagement could be seen as a consequence of their understanding and acceptance of the need for TDM, their trust in the data provided, and their belief that the Games would have a positive impact on the city. Those businesses directly impacted by the road restrictions of the ORN had little choice to engage. Due to TfL's proactive involvement, these businesses understood the requests made of them and so the antecedents for a balanced exchange were realized.

Engagement with small organizations and microbusinesses was more problematic. With such a large number of organizations, and their "short-termist" nature, it meant that it was difficult for TfL to engage them early in the planning process. They gleaned much of their information through the press or via trade associations, as direct involvement with TfL was limited. However, there was little they could do in the sense of retime, reroute, remode, or reduce. TfL concentrated on managing their expectations and providing advice for their business continuity. Our research identified that many small businesses were ill informed and, consequently, they were very concerned about the impact of TDM on their operations. They found themselves in a relationship with little control or influence and became increasingly negative as to the benefits the Games may bring. Consequently, antecedents were not realized, resulting in no engagement or creating an imbalance in the exchange, resulting in a negative evaluation. This is similar to Waitt's (2003) findings where, as the Games neared, Sydney residents became increasingly more negative. Also Cheng and Jarvis' (2010) study identified that perceptions of road congestion resulted in an imbalance in the exchanges as residents did not realize any benefits. Although fearful of the short-term effects on their continued operations, London's small businesses were still hopeful for the longer term benefits the Games might bring. Comparison cannot be made with Waitt's (2003) altruistic themes. For these small businesses, which had been struggling to cope in a difficult economic climate, their individual business survival took precedence over any altruistic tendencies.

The impact of messages derived from the media was identified to be a powerful tool in influencing certain areas of the business community to realize antecedents necessary for the exchange. Though this could work in TfL's favor, as it enhanced awareness and evoked action. Some messages did become distorted and resulted in an increase in negative attitudes. Small businesses not receiving a coherent message direct from TfL were particularly receptive to this channel of communication. TfL claimed to have little or no influence over the media. However, by being proactive and ensuring the correct information was clearly available, including the use of third parties, certain aspects of the negativity could have been reduced and may have helped realize some aspect of the antecedents, allowing for a more positive evaluation of the exchange. As Tim alluded to in his interview, it was 
the FSB that initiated dialogue with TfL to ensure the correct information was being communicated.

Whether the transport authorities directly used the press to shock stakeholders into reaction is difficult to confirm. Nevertheless, there is a belief that scare tactics have been used in transport management for previous Olympic Games (Clean Air in London, 2011; Currie, 1998; Shawcross, 2011) and, as our interviewees noted, stories in the press are very effective at encouraging engaging with TDM. Scare tactics are also evident in TfL's presentations as the image of "Atlanta” so clearly demonstrates. It is evident that to ensure business engagement in TDM, the message needs to be understood and acted on and the use of horror stories would appear to be part of that process. The confusion of the 100 days of the ORN is a case in point. Originally, business believed the 100 days story, imagining that the restrictions would be "devastating." However, they were so relieved by the clarification of the reduced period that they were happy to comply and engaged proactively with the more limited restrictions.

The exchange relationship between business and the authorities will not necessarily involve all antecedents but their presence or absence will affect the balance of the exchange relationship (Ap, 1992), and thereby the outcome and their level of engagement. The results indicate that the size of the organization and level of control affect the ability to realize antecedents in the exchange relationship. Where the antecedent conditions are not met or companies have not been part of the engagement process, they bypass the exchange relationship. Where the event has prestige, such as the Olympic Games, it influences the antecedent conditions. An element of altruism is evident when a company, for the greater good, goes beyond what is requested by the authorities, which could be attributed to its CSR. The desire for future participation is limited for events such as the Olympic Games as it is usually held in a location once in a lifetime.

\section{Conclusion}

This research adds to the knowledge of megaevent management and the processes required for successful policy engagement. It is important to understand how business reacts to requests to ensure the success of an event made of them by authorities.
This is especially important when these organizations do not believe they will directly benefit from the event. To encourage exchange authorities have to implement a comprehensive and targeted engagement policy. To realize the antecedents necessary for a positive exchange, business must fully understand the implications of their actions or inactions and the effect this could have on the transport network, their business continuity, and the success of the event. The importance of the event could evoke a "responsibilities to the wider community" view. This "responsibility" may have acted as a driver for change by large businesses that were happy to engage with TDM measures even in the knowledge that it would incur additional costs. Medium and smaller-sized businesses, though supportive of the event, rely on the resilience of their employees to ensure minimal disruption, and costs are kept to an absolute minimum. Individuals' engagement with TDM was not in this study's remit and further research into the employeremployee relationship in engaging in such policies is recommended to shed further light on this complex engagement process for mega-events.

The Olympics is regarded as the most prestigious event a city can hold, yet many businesses interviewed were not prepared, or able, to take steps to help reduce the base load, despite a comprehensive and proactive communication strategy. Therefore, to ensure success, a tailored communication approach specific to the size of organization is recommended. As our research has shown, for a positive exchange to occur most of the antecedents need to be realized, the larger organizations felt in control, well briefed, and able and willing to comply with the requirements of TDM. Smaller organizations, depending on the level of communication, complied to a lesser and varying extent. It could be argued that TfL's strategy was comprehensive and capable of achieving its goal of "influencing enough people enough," but as our study has shown, many organizations were not influenced enough. Early consultation with organizations whose operations were directly affected by TDM could have diffused some inaccuracies and unnecessary negativities. A more targeted campaign focused at small and medium-sized businesses through organizations such as FSB could also have alleviated fears and helped correct the imbalance in the exchange relationship. It would not be realistic to expect TfL's strategy to be able to influence 
most businesses. However, due to the uncertainty of compliance levels, lessons should be learned to ensure better engagement from these more marginalized organizations. The influence of "scare stories" should not be overlooked. However, authorities need to evaluate the implications of using such tactics as they may not always have the desired effect.

If the event does not have the popular appeal of the Olympic Games, which encourages an element of altruistic behavior, authorities may need to identify and promote positive aspects of the event to help influence the realization of antecedents necessary to ensure a mutually positive exchange. Consideration needs to be given to the fact that this TDM policy cost $£ 30$ million (Currie et al., 2013) and had no tangible deliverables. If this TDM approach achieves its objectives, will this cost be viewed as efficient use of resources, and what are its legacy impacts, if any?

This is an exploratory study involving a relative small number of businesses. To test these initial findings into impacts of mega-events on businesses, a larger sample would be recommended. To identify the success factors of the TDM strategy, research including interviewing the same businesses postGames would also be recommended and the role of this TDM policy in producing a sustainable legacy for the city needs to be evaluated.

\section{References}

Ap, J. (1992). Residents' perceptions on tourism impacts. Annals of Tourism Research, 19, 665-690.

Applebome, P. (1996). Atlanta: Day 4-Traffic; Athletes' challenges: Getting there. The New York Times. Retrieved June 17, 2012, from http://www.nytimes.com/1996/07/23/ sports/atlanta-day-4-traffic-athletes-challenge-gettingthere.html

Auerbach, C., \& Silverstein, L. (2003). Qualitative data: An introduction to coding and analysis. London/New York: University Press.

Baker, M. (2004). Crime and sport event tourism: The 1999-2000 America's Cup. In B. Ritchie \& D. Adair (Eds.), Sports tourism: Interrelationships, impacts and issue 9 (Ch. 9, e-book). Clevedon, UK: Channel View Publications.

Barker, M., Page, S. J., \& Meyer, D. (2002). Evaluating the impact of the 2000 America's Cup on Auckland, New Zealand. Event Management, 7(2), 79-92.

Bautz, J. A. (1988). Suburban gridlock. Fighting congestion to improve mobility. Transportation Research News, 138, 8-10.
Bhattacharjee, D., Haider, W., Tanaboriboon, Y., \& Sinha, K. (1997). Commuters' attitudes towards travel demand management in Bangkok. Transport Policy, 4(3), 161-170.

Bovy, P. (2006). Solving outstanding mega-event transport challenges: The Olympic experience. Public Transport International, 6, 2-34.

Bovy, P. (2007). Transport and mobility management challenges for the world's largest mega-event: 1992 to 2012 Summer Olympic Games. UC-Berkeley-Institute of Transportation Studies. Retrieved May 30, 2012, from http:// www.mobility-bovy.ch/resources/16_BERKELEY-07.pdf

Bovy, P. (2010). Olympic transport and sustainability. UBC Vancouver 2010. Think Tank on Sport, Events and Sustainability. Retrieved June 20, 2012, from http://www. mobility-bovy.ch/resources/10.UBC-Sustainability.pdf

Boyko, C. T. (2008). Are you being served? The impacts of a tourist hallmark event on the place meanings of residents. Event Management, 11(4), 161-177.

Brown, G., Chalip, L., Jago, L., Mules, T., \& Morgan, N. (2002). The Sydney Olympics and brand Australia. In N. Morgan, A. Pritchard, \& R. Pride (Eds.), Destination branding: Creating the unique destination proposition (pp. 163-185). Oxford: Butterworth.

Cegielski, M., \& Mules, T. (2002). Aspects of residents' perceptions of the GMC 400-Canberra's V8 Supercar Race. Current Issues in Tourism, 5(1), 54-70.

Chalip, L., \& Leyns, A. (2002). Local business leveraging of a sport event: Managing an event for economic benefit. Journal of Sport Management, 16, 132-158.

Cheng, E., \& Jarvis, N. (2010) Residents' perception of the social-cultural impacts of the Formula 1 Singtel Singapore Grand Prix. Event Management, 14, 91-106.

Clean Air in London. (2011). Plans for the Olympic route network remain unlawful and vulnerable to legal challenge through judicial review. Retrieved July 3, 2012, from http://cleanair.london/olympics/plans-for-the-olympicroute-network-remain-unlawful-and-vulnerable-tolegal-challenge-through-judicial-review

Currie, G. (1998). The planning and performance of mass transit operating strategies for major events: The Atlanta Olympic Games and the 1996 Melbourne Formula 1 Grand Prix. Australian Institute of Traffic Planning and Management (AITPM) Conference 1998, Melbourne, Australia.

Currie, G., \& Delbosc, A. (2011). Assessing travel demand management for the summer Olympics Games. Transportation Research Record: Journal of the Transportation Research Board, 2245, 36-48.

Currie, G., Jones, A., \& Woolley, J. (2013). The travel demand management program for the London 2012 Olympic Games-Impacts and lessons. Paper presented at the 13th WCTR (The World Conference on Transportation Research), Rio de Janeiro, Brazil.

Currie, G., \& Shalaby, A. (2011). Synthesis of transport planning approaches for the world's largest events. Transport Reviews, 32(1), 113-136.

Deccio, C., \& Baloglu, S. (2002). Nonhost community resident reactions to the 2002 Winter Olympics: The spillover impacts. Journal of Travel Research, 41(1), 46-56. 
Dobson, N., \& Sinnamon, R. (2001). A critical analysis of the organisation of major sports events. In C. Gratton \& I. P. Henry (Eds), Sport in the city: The role of sport in economic and social regeneration (pp. 63-77). London: Routledge.

Dosunmu, B. (2012). Delivering London 2012: Transport demand forecasting. Proceedings of the ICE - Transport, 165(4), 257-266.

Dwyer, L., Mellor, R., Mistilis, N., \& Mules, T. (2000). A framework for assessing "tangible" and "intangible" impacts of events and conventions. Event Management, 6(3), 175-189.

Emerson, R. (1976). Social exchange theory. Annals Review of Sociology, 2, 335-362.

Enoch, M., \& Potter, S. (2003). Encouraging the commercial sector to help employees to change their travel behaviour. Transport Policy, 10, 51-58.

Essex, S., \& Chalkley, B. (2003). Urban transformation from hosting the Olympic Games. University lecture on the Olympics, Centre d'Estudis Olimpics, Univesitat Autonoma de Barcelona.

Faulkner, B., \& Tideswell, C. (1997). A framework for monitory community impacts of tourism. Journal of Sustainable Tourism, 5(1), 3-28.

Ferguson, E. (1990). Transportation demand management planning, development, and implementation. Journal of the American Planning Association, 56(4), 442-456.

Fredline, E. (2005). Host and guest relations and sport tourism. Sport in Society, 8(2), 263-279.

Fredline, E., \& Faulkner, B. (1998). Residents' reaction to a major tourism event: The Gold Coast Indy Car Race. Festival and Event Tourism, 5, 185-205.

Fredline, E., \& Faulkner, B. (2002). Variations in residents' reaction to major motorsport events: Why residents perceive the impacts of events differently. Event Management, 7(2), 115-125.

Flyvberg, B., Bruzelius, N., \& Rothengatter, W. (2003). Megaprojects and risk. Cambridge: Cambridge University Press.

Fontana, A., \& Frey, J. H. (1994). Interviewing: The art of science. In N. Denzin \& Y. Lincoln (Eds.), Handbook of qualitative research, (pp. 361-377). London: Sage.

Geertz, C. (1973). The interpretation of cultures: Selected essays. New York: Basic Books.

Getz, D. (2002). Why festivals fail. Event Management, 7(4), 209-219.

Giuliano, G. (1992). Transportation demand management: Promise or panacea? Journal of the American Planning Association, 58(3), 327-335.

Gursoy, D., \& Kendall, K. W. (2006). Hosting mega events: Modeling locals' support. Annals of Tourism Research, 33(3), 603-623.

Hall, C. M. (1992). Hallmark tourist events: Impacts, management and planning. London: Belhaven.

Hall, C. M. (2006). Urban entrepreneurship, corporate interests and sports mega-events: The thin policies of competitiveness within the hard outcomes of neoliberalism. In J. Horne \& W. Manzenreiter (Eds.), Sports mega-events: Social scientific analysis of a global phenomenon (pp. 59-70). Oxford: Blackwell Publishing Ltd.

Haralambopoulos, N., \& Pizam, A. (1996). Perceived impacts of tourism: The case of Samos. Annals of Tourism Research, 23(3), 503-526.

Haxton, P. (1999). Community involvement and the Olympic Games: A review of related research. In Report on the IOA'S special sessions and seminars (pp. 142-164). Athens: International Olympic Academy.

Heckathorn, D. (2002). Respondent-driven sampling II: Deriving valid population estimates from chain-referral samples of hidden populations. Social Problems, 49(1), 11-34.

Hendy, P. (2012). Hosting a great Games and keeping London moving this summer. Retrieved March 22, 2012, from https://www.tfl.gov.uk/cdn/static/cms/documents/Item07Final-Preparations-for-the-London-2012-Games.pdf

Hensher, D. A., \& Brewer, A. M. (2002). Going for Gold at the Sydney Olympics: How did the transport perform? Transport Reviews, 22(4), 381-399.

Hiller, H. (2000). Mega-events, urban Boosterism and growth strategies: An analysis of the objectives and legitimations of the Cape Town 2004 Olympic bid. International Journal of Urban and Regional Research, 24(2), 439-458.

House of Lords. (2005). Delegated powers and regulatory reform-eleventh report. Retrieved July 3, 2012, from http://www.publications.parliament.uk/pa/ld200506/ ldselect/lddelreg/95/95.pdf

Jago, L., Chalip, L., Brown, G., Mules, T., \& Ali, S. (2003). Building events into destination branding: Insights from experts. Event Management, 8(1), 3-14.

Jessop, B. (2002). Liberalism, neo-liberalism, and urban governance: A stance-theoretical perspective. Antipode, 34, 452-472.

Jones, A., \& Woolley, J. (2013). Global events and local conflicts: Who owns the streets of London? In U. Merkel (Ed.), Power, politics and international events: Socio-cultural analyses of festivals and spectacles (Routledge Advances in Event Research Series, pp. 105-125). Abingdon, UK: Routledge.

Jones, C. (2001). Mega-events and host region impacts: Determining the true worth of the 1999 Rugby World Cup. International Journal of Tourism Research, 3, 241-251.

Kassens-Noor, E. (2012). Planning Olympic legaciestransport dream and urban realities. Abingdon, UK/ New York: Routledge.

Kershaw, S. (2012). Delivering London 2012: Transport programme assurance. Proceedings of the Institution of Civil Engineers-Transport, 165(4), 241-248.

Kim, H. J., Gursoy, D., \& Lee, S. B. (2006). The impact of the 2002 World Cup on South Korea: Comparisons of preand post-games. Tourism Management, 27(1), 86-96.

Loukopoulos, P. (2007). A classification of travel demand management measures. In T. Gärling \& L. Steg (Eds.), Threats from car traffic to the quality of urban life: Problems, causes, and solutions (pp. 275-292). Amsterdam: Elsevier. 
Miles, M., \& Huberman, A. (1994). An expanded sourcebook: Qualitative data analysis (2nd ed.). London: Sage.

Minis, I., \& Tsamboulas, D. (2008). Contingency planning and war gaming for the transport operations of the Athens 2004 Olympic Games. Transport Reviews, 28(2), 259-280.

Meuser, M., \& Nagel, U. (2002). Expert inneninterviewsvielfach erprobt, wenig bedacht. In A. Nogner, B. Littig, \& W. Menz (Eds.), Das Experteninterview Opladen (pp. 71-93). Leske and Budrich.

Moser, G., \& Bamberg, S. (2008). The effectiveness of soft transport policy measures: A critical assessment and meta-analysis of empirical evidence. Journal of Environmental Psychology, 2, 10-26.

Nunkoo, R., \& Ramkisson, H. (2012). Power trust, social exchange and community support. Annals of Tourism Research, 39(2), 997-1023.

O’Brien, D. (2006). Event business leveraging: The Sydney 2000 Olympic Games. Annals of Tourism Research, 33(1), 240-261.

Ohmann, S., Jones, I., \& Wilkes, K. (2006). The perceived social impacts of the 2006 Football World Cup on Munich residents. Journal of Sport \& Tourism, 11(2), 129-152.

Olympic Delivery Authority. (2010). Keep on running. Retrieved February 20, 2012 from http://doc.rero.ch/ record/22383/files/traveladviceforbusiness-handbook.pdf

Olympic Delivery Authority. (2012). Introduction to London 2012 travel demand management. London: Author.

Onwuegbuzie, A., \& Leech, N. (2007). A call for qualitative power analyses. Quality \& Quantity, 41, 105-121.

Pettigrew, A. (1990). Longitudinal field research on charge: Theory and practice. Organizational Science, 3(1), 267-292.

Perdue, R., Long, P., \& Allen, L. (1990). Residents’ support for tourism development. Annals of Tourism Research, 7, 586-599.

Ponsford, I., \& Williams, P. (2010). Crafting a social license to operate: A case study of Vancouver 2010's Cypress Olympic Venue. Event Management, 14, 17-36.

Pranic, L., Petric, L., \& Cetinic, L. (2012). Host population perceptions of the social impacts of sports tourism events in transition countries: Evidence from Croatia. International Journal of Event and Festival Management, 3(3), 236-256.

Richards, G., Carlsen, J., Robertson, M., \& Ali-Knight, J. (2007). Culture and authenticity in a traditional event: The views of producers, residents, and visitors in Barcelona. Event Management, 11(1/2), 33-44.

Ritchie, B. (1984). Assessing the impact of hallmark events: Conceptual and research issues. Journal of Travel Research, 2-11.

Robbins, D., Dickinson, J., \& Calver, S. (2007). Planning transport for special events: A conceptual framework and future agenda for research. International Journal of Tourism Research, 9, 303-314.
Roby, H. (2010). Workplace travel plans: Past, present and future. Journal of Transport Geography, 18, 23-30.

Roper, A. (2004). Marketing standardisation: Tour operators in the Nordic region. European Journal of Marketing, 39(5/6), 514-527.

Searle, M. (1991). Propositions for testing social exchange theory in the context of ceasing leisure participation. Leisure Sciences, 13, 279-294.

Schimmel, K. S. (2006). Deep play: Sports, mega-events and urban social conditions in the USA. In J. Horne \& W. Manzenreiter (Eds.), Sports mega-events: Social scientific analysis of a global phenomenon (pp. 160-174). Oxford: Blackwell Publishing Ltd.

Shawcross, V. (2011). Clearing the hurdles: Transport for the 2012 Olympic and Paralympic Games. London: Greater London Authority.

Small, K., Carlsen, J., Robertson, M., \& Ali-Knight, J. (2007). Social dimensions of community festivals: An application of factor analysis in the development of the Social Impact Perception (SIP) scale. Event Management, 11(1/2), 45-55.

Sutton, Jr., W. A. (1967). Travel and understanding: Notes on the social structure of touring. Journal of Comparative Sociology, 8, 218-223.

Tanaboriboon, Y. (1994). Demand management. An alternative approach to relieve traffic congestion in developing countries: Asian metropolises context. Proceedings, Japan Society of Civil Engineers. Dohoku Gakkai Ronbun Heokokusheu, 488, 11-19.

TNS-BMRB. (2012). Inspiring a generation: A taking part report on the 2012 Olympic and Paralympic Games. Retrieved August 7, 2012 from, https://www.gov.uk/ government/uploads/system/uploads/attachment_data/ file/78316/Taking_Part_Olympic_Report.pdf

Tomlinson, A. (1996). Olympic spectacle: Opening ceremonies and some paradoxes of globalization. Media, Culture \& Society, 18(4), 583-602.

Voss, C., Tsikriktsis, N., \& Frohlich, M. (2002). Case research in operations management. International Journal of Operations and Production Management, 22(2), 195-219.

Ward, C., \& Berno, T. (2011). Beyond social exchange theory: Attitudes towards tourists. Annals of Tourism Research, 38(4), 1566-1569.

Waitt, G. (2003). Social impacts of the Sydney Olympics. Annals of Tourism Research, 30(1), 149-215.

Wrong, D. (1979). Power as forms, bases and uses. New York: Harper and Row.

Yin, R. (2003). Case study research design and method. London: Sage.

Zhou, Y., \& Ap, J. (2008). Residents’ perceptions towards the impacts of the Beijing 2008 Olympic Games. Journal of Travel Research, 48, 78-91. 